\title{
Increased oxidoreduction of deoxycholic acid in cholecystectomised patients
}

\author{
K EINARSSON, K NILSELL, AND I BJÖRKHEM \\ From the Departments of Medicine, Surgery and Clinical Chemistry, Karolinska Institute at Huddinge \\ University Hospital, Huddinge, Sweden
}

\begin{abstract}
SUMMARY The extent of oxidoreduction of deoxycholic acid in the enterohepatic circulation was studied in seven healthy subjects and seven patients after cholecystectomy. $\left(12 \beta-{ }^{3} \mathrm{H}\right)$ Deoxycholic acid was given orally together with $\left(24-{ }^{14} \mathrm{C}\right)$ labelled bile acid. The rate of oxidoreduction of the $12 \alpha-$ hydroxyl group of deoxycholic acid was calculated from the decay in ratio between ${ }^{3} \mathrm{H}$ and ${ }^{14} \mathrm{C}$. In spite of a normal proportion of deoxycholic acid and other secondary bile acids in bile, patients after cholecystectomy had more than two-fold higher degree of oxidoreduction of the $12 \alpha$-hydroxyl group than healthy controls. The high extent of oxidoreduction is probably because of an increased exposure of the bile acid pool to intestinal bacteria and may have physiological implications.
\end{abstract}

Bile acids are subjected to extensive microbial biotransformations in the intestine, including deconjugation, $7 \alpha$-dehydroxylation and oxidoreduction.' Portal venous serum from fasting man contains about $10 \%$ of monoketonic bile acids. ${ }^{2}$ In the liver reabsorbed bile acids are reconjugated - but not rehydroxylated - and keto groups are reduced, mainly to $\alpha$-hydroxyl groups. ${ }^{34}$ Consequently, human bile normally contains only traces of ketonic bile acids whereas they may represent a significant fraction of human faecal bile acids. ${ }^{5-7}$

Some investigations of bile acid metabolism have shown an increase of secondary bile acids, especially deoxycholic acid in the bile of cholecystectomised patients. ${ }^{-12}$ An increased proportion of ketonic bile acids has also been reported. ${ }^{41}$ Since there are oxidoreductases both in the intestine and in the liver, it is not possible to evaluate the total extent of oxidoreduction of bile acids during the enterohepatic circulation from the above information. ${ }^{34}$

We have recently studied the extent of oxidoreduction of the hydroxyl groups in cholic acid and deoxycholic acid during the enterohepatic circulation in healthy man. ${ }^{13}$ The degree of oxidoreduction was

Address for correspondence: Dr Kurt Einarsson, Department of Medicine, Huddinge University Hospital, s-141 86 Huddinge, Sweden.

Accepted for publication 16 January 1989. considerably higher for deoxycholic acid than for cholic acid. In the present work we have studied the extent of oxidoreduction of deoxycholic acid in cholecystectomised patients with use of deoxycholic acid labelled in $12 \beta$-position. The ${ }^{3} \mathrm{H}$-labelled bile acid was given together with the corresponding 24${ }^{14} \mathrm{C}$-labelled bile acid. The rate of oxidoreduction was calculated from the decay in ratio between ${ }^{3} \mathrm{H}$ and ${ }^{14} \mathrm{C}$. According to the results obtained, cholecystectomised patients have more than two times higher rate of oxidoreduction of deoxycholic acid than healthy controls.

\section{Methods}

PATIENTS

The study comprised five healthy men and two healthy women with no signs of liver or intestinal diseases and seven women who had undergone cholecystectomy for cholesterol gall stones at least six months before this study (Table 1). None of the patients had received antibiotic therapy during the last two months preceding the study and none was on treatment with any medication known to affect plasma or biliary lipid metabolism.

The ethical aspects of the study were approved by the Ethical Committee at Huddinge University Hospital. 
MATERIALS

$\left(12 \beta-{ }^{3} \mathrm{H}\right)$ Deoxycholic acid (specific radioactivity $83 \times 10^{6} \mathrm{cpm} / \mathrm{mg}$ ) was synthesised as recently described.$^{13}\left(24-{ }^{14} \mathrm{C}\right)$ Deoxycholic acid (specific radioactivity $220 \times 10^{6} \mathrm{cpm} / \mathrm{mg}$ ) was obtained from New England Nuclear (Dreieichenhain, West-Germany). The compounds were purified as methyl esters by thin layer chromatography using system S 11 before use. ${ }^{14}$ The free steroid was prepared from the methyl ester by alkaline hydrolysis. The ${ }^{3} \mathrm{H}$-labelled bile acid was mixed with the ${ }^{14} \mathrm{C}$-labelled bile acid to give a ${ }^{3} \mathrm{H} /{ }^{14} \mathrm{C}$ ratio of about $2 \cdot 5-3 \cdot 0$. The amount of ${ }^{3} \mathrm{H}$ given was about $8 \times 10^{6} \mathrm{cpm}$, the amount of ${ }^{14} \mathrm{C}$ about $3 \times 10^{6} \mathrm{cpm}$ and the weight of labelled material about $110 \mu \mathrm{g}$.

ADMINISTRATION OF LABELLED BILE ACIDS

AND COLLECTION OF BILE

The labelled bile acid mixture was given as a sodium salt dissolved in water in the evening. Samples of duodenal bile were collected each morning for the four following days. Cholecystokinin was administered intravenously, and about $5 \mathrm{ml}$ of concentrated duodenal bile was obtained through a thin polyvinyl tube with the collecting orifice positioned fluoroscopically at the ampulla of Vater.

ANALYSIS OF BILE ACIDS

The duodenal bile samples were hydrolysed with $1 \mathrm{M}$

Table 1 Fractional catabolic rate (FCR) of the $12 \alpha$ hydroxyl group in deoxycholic acid, determined in healthy subjects and cholecystectomised patients

\begin{tabular}{|c|c|c|c|c|c|}
\hline \multirow[b]{2}{*}{ Subject number } & \multirow{2}{*}{\multicolumn{2}{|c|}{$\begin{array}{r}\text { Age } \\
\text { Sex }(y r)\end{array}$}} & \multicolumn{2}{|c|}{ Body weight } & \multirow[b]{2}{*}{$F C R / d a y$} \\
\hline & & & $\mathrm{kg}$ & $\begin{array}{l}\% \text { of } \\
\text { ideal }^{*}\end{array}$ & \\
\hline \multicolumn{6}{|l|}{ Healthy subjects } \\
\hline 1 & $\mathrm{~F}$ & 29 & 51 & 79 & $0 \cdot 17$ \\
\hline 2 & $\mathrm{~F}$ & 68 & 56 & 98 & $0 \cdot 19$ \\
\hline 3 & M & 28 & 70 & 92 & $0 \cdot 27$ \\
\hline 4 & M & 21 & 71 & 82 & $0 \cdot 27$ \\
\hline 5 & M & 29 & 67 & 88 & $0 \cdot 15$ \\
\hline 6 & M & 31 & 80 & 89 & $0 \cdot 18$ \\
\hline 7 & M & 30 & 75 & 88 & 0.09 \\
\hline Mean (SEM) & & $34(6)$ & $67(4)$ & $88(2)$ & $0 \cdot 19(0 \cdot(2)$ \\
\hline \multicolumn{6}{|c|}{ Cholecystectomised patients } \\
\hline 8 & $\mathrm{~F}$ & 67 & 69 & 114 & 0.41 \\
\hline 9 & $\mathrm{~F}$ & 58 & 65 & 102 & $0 \cdot 38$ \\
\hline 10 & $\mathrm{~F}$ & 36 & 69 & 101 & $0 \cdot 60$ \\
\hline 11 & $\mathrm{~F}$ & 20 & 60 & 86 & 0.50 \\
\hline 12 & $\mathbf{F}$ & 38 & 63 & 90) & $0 \cdot 26$ \\
\hline 13 & $\mathrm{~F}$ & 44 & 82 & 137 & $0 \cdot 26$ \\
\hline 14 & $\mathrm{~F}$ & 72 & 58 & 100 & 0.50 \\
\hline Mean (SEM) & & $48(7)$ & $67(3)$ & $104(6)$ & $0.42(0.05)$ \\
\hline
\end{tabular}

$\mathrm{KOH}$ in closed steel tubes for 12 hours at $110^{\circ} \mathrm{C}$. After acidification, the deconjugated bile acids were extracted with ethyl ether and methylated with diazomethane. One aliquot was subjected to thin layer chromatography using system S 11 to isolate the methyl ester of deoxycholic acid. ${ }^{14}$ The purity of the bile acid was checked by gas liquid chromatography as the methyl ester trimethylsilyl derivative, using a $1.5 \%$ SE-30 column. Radioactivity was measured with an Intertechnique SL 30 liquid scintillation spectrometer, using Lumal gel (LUMAC, BV, The Netherlands) as scintillation fluid. Under the conditions used the counting efficiency was $49 \%$ for ${ }^{3} \mathrm{H}$ and $71 \%$ for ${ }^{14} \mathrm{C}$. No corrections for quenching were found to be necessary. For determination of bile acid composition, another aliquot of the methylated bile acid extract was trimethylsilylated and analysed by gas liquid chromatography using a $1.5 \%$ SE-30 column.

\section{STATISTICAL ANALYSIS}

Data are presented as means (SEM). The statistical significance of differences was evaluated by Student's $t$ test. Correlations were tested by estimating the correlation coefficient $r$.

\section{Results}

As seen in the Figure the ${ }^{3} \mathrm{H} /{ }^{14} \mathrm{C}$ ratio in deoxycholic acid decreased with time in the healthy subject as well

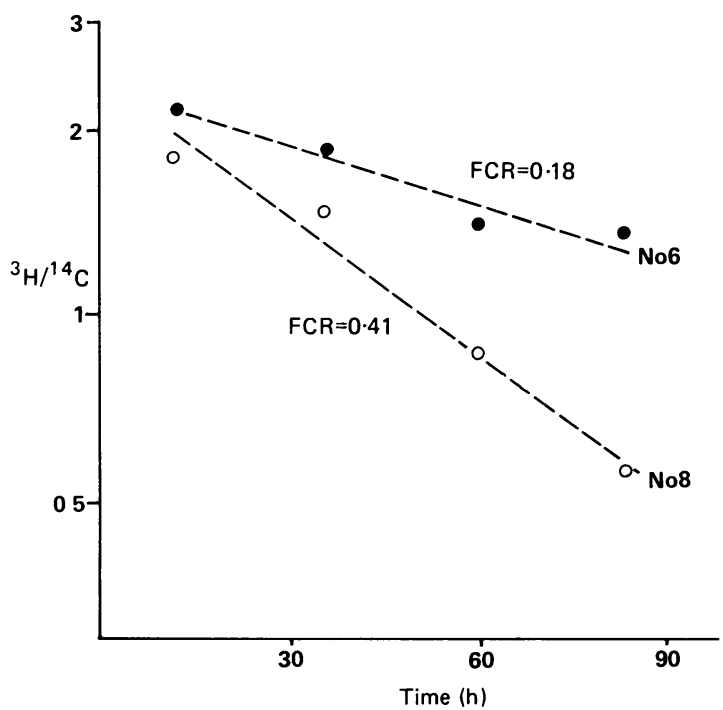

Figure Decay of ${ }^{3} \mathrm{H}^{14} \mathrm{C}$ ratio in deoxycholic acid isolated from duodenal bile of a healthy subject (no 6) and a cholecystectomised patient (no 8) after oral administration of $\left(12 \beta-{ }^{3} \mathrm{H}\right)$ - and $\left(24-{ }^{14} \mathrm{C}\right)$ deoxycholic acid. 
Table 2 Biliary bile acid composition (\%) in healthy subjects and cholecystectomised patients

\begin{tabular}{|c|c|c|c|c|c|}
\hline Subject number & $\begin{array}{l}\text { Cholic } \\
\text { acid }\end{array}$ & $\begin{array}{l}\text { Chenodeoxycholic } \\
\text { acid }\end{array}$ & $\begin{array}{l}\text { Deoxycholic } \\
\text { acid }\end{array}$ & $\begin{array}{l}\text { Ursodeoxycholic } \\
\text { acid }\end{array}$ & $\begin{array}{l}\text { Lithocholic } \\
\text { acid }\end{array}$ \\
\hline \multicolumn{6}{|l|}{ Healthy subjects } \\
\hline 1 & $45 \cdot 9$ & $38 \cdot 2$ & $15 \cdot 9$ & - & - \\
\hline 2 & $35 \cdot 3$ & $44 \cdot 0$ & $16 \cdot 5$ & $2 \cdot 3$ & 1.9 \\
\hline 3 & $37 \cdot 6$ & $32 \cdot 7$ & $28 \cdot 7$ & 0.7 & $0 \cdot 3$ \\
\hline 4 & $40 \cdot 0$ & $38 \cdot 2$ & $18 \cdot 4$ & $3 \cdot 4$ & trace \\
\hline 5 & $47 \cdot 9$ & $21 \cdot 1$ & $30 \cdot 1$ & - & 0.9 \\
\hline 6 & $45 \cdot 0$ & $30 \cdot 4$ & $22 \cdot 8$ & 1.5 & $0 \cdot 3$ \\
\hline 7 & $51 \cdot 1$ & $34 \cdot 8$ & $13 \cdot 0$ & trace & $1 \cdot 2$ \\
\hline Mean (SEM) & $43 \cdot 2(2 \cdot 2)$ & $34 \cdot 2(2 \cdot 8)$ & $20 \cdot 8(2 \cdot 5)$ & $1 \cdot 1(0 \cdot 5)$ & $0.7(0 \cdot 3)$ \\
\hline \multicolumn{6}{|c|}{ Cholecystectomised patients } \\
\hline 8 & $28 \cdot 8$ & $22 \cdot 5$ & $41 \cdot 4$ & $3 \cdot 8$ & $3 \cdot 5$ \\
\hline 9 & $48 \cdot 1$ & $32 \cdot 6$ & $18 \cdot 8$ & trace & $0 \cdot 5$ \\
\hline 10 & $33 \cdot 5$ & $39 \cdot 8$ & $23 \cdot 1$ & - & $3 \cdot 6$ \\
\hline 11 & $45 \cdot()$ & $34 \cdot 8$ & $15 \cdot 2$ & $1 \cdot 0$ & $4 \cdot 0$ \\
\hline 12 & $35 \cdot 1$ & $28 \cdot 3$ & $32 \cdot 1$ & $4 \cdot 0$ & 0.5 \\
\hline 13 & $41 \cdot 1$ & 33.9 & $16 \cdot 0$ & $7 \cdot 4$ & $1 \cdot 6$ \\
\hline 14 & $44 \cdot 4$ & $31 \cdot 8$ & $20 \cdot 1$ & $3 \cdot 7$ & - \\
\hline Mean (SEM) & $39 \cdot 4(2 \cdot 7)$ & $32 \cdot 0(2 \cdot 1)$ & $23 \cdot 8(3 \cdot 6)$ & $2 \cdot 8(1 \cdot 0)$ & $2 \cdot 0(0 \cdot 6)$ \\
\hline
\end{tabular}

as in the cholecystectomised patient. The correlation coefficient for the decay curve averaged $0.953(0.023)$ in the healthy subjects and $0.995(0.003)$ in the cholecystectomised patients. The fractional conversion rate (FCR) for the $12 \alpha$-hydroxyl group in deoxycholic acid, calculated from the decrease in ${ }^{3} \mathrm{H} /{ }^{14} \mathrm{C}$ ratio averaged $0 \cdot 19 /$ day in the healthy subjects (Table 1). Corresponding FCR was more than twofold higher in the cholecystectomised patients (mean value $0 \cdot 42 /$ day $)(p<0 \cdot 01)$ (Table 1$)$. The biliary bile acid composition in the healthy subjects and the cholecystectomised patients is shown in Table 2. The percentage proportion of deoxycholic acid was not significantly increased in the cholecystectomised patients. The proportion of secondary bile acids (deoxycholic acid+ursodeoxycholic acid+lithocholic acid) tended to be higher in the cholecystectomised patients $(28.6(4.0) \%)$ compared with the healthy subjects $(21.3(2.6) \%)$ but the difference did not reach statistical significance $(\mathrm{p}>0 \cdot 05)$.

\section{Discussion}

In the present study the percentage proportion of deoxycholic acid was not significantly raised in the cholecystectomised patients. This finding is contrary to some previous studies reporting $50-100 \%$ higher proportion of deoxycholic acid in cholecystectomised subjects compared with healthy controls. ${ }^{812-12} \mathrm{~A}$ high level of deoxycholic acid has been ascribed to an increased bacterial $7 \alpha$-dehydroxylation of cholic acid. Because dehydroxylation is a function of the colonic flora an increased bacterial transformation after cholecystectomy, may be because the bile acid pool spends a greater part of the 24 hours in the intestine, especially the colon, being exposed to the intestinal microflora to a greater extent than normally. An increased proportion of deoxycholic acid after cholecystectomy, however, has not been found in all studies. ${ }^{41516}$ Whether this discrepancy is caused by differences in intestinal microflora and/or dietary intake in the patient groups investigated can presently not be established with certainty.

A new and important finding of the present study was the high oxidoreduction of the $12 \alpha$-hydroxyl group of deoxycholic acid in cholecystectomised patients, being more than twice as high as in healthy controls. As was discussed in a recent work from our laboratory ${ }_{1.3}^{13}$ the present technique should give a minimum figure for the extent of oxidoreduction for the following reasons: first, there may be an isotope effect in the oxidation of the $12 \alpha$-hydroxyl group adjacent to the $12 \beta-{ }^{3} \mathrm{H}$-label. Second, a transfer of ${ }^{3} \mathrm{H}$ may occur from the labelled bile acid to a cofactor of the $12 \alpha$-hydroxysteroid dehydrogenase in the oxidative step and a subsequent utilisation of the same labelled cofactor by the hydroxysteroid dehydrogenase in the reductive step. Such a mechanism would lead to a certain retention in the bile acid in spite of an oxidoreduction. Therefore, we cannot exclude a small underestimation of the oxidoreduction in the present study.

It should be pointed out, that there are also oxidoreductases present in the liver and it might therefore be argued that part of the oxidoreduction of the $12 \alpha$-hydroxyl group could occur in the liver. In a previous work we tried to evaluate the relative roles of the liver and intestine by studying the oxidoreduc- 
tion of $\left(12 \beta-{ }^{-3} \mathrm{H}\right)$ deoxycholic acid in two patients with ileostomy. ${ }^{13}$ The FCR for the oxidoreduction of the $12 \alpha$-hydroxyl group was less than $20 \%$ of that obtained in healthy controls. It is thus apparent that the intestine is of major importance for the oxidoreduction of the $12 \alpha$-hydroxyl group in deoxycholic acid. In cholecystectomised patients there is an increased recycling of bile acids and an increased exposure of the bile acid pool to bacterial metabolism, which may explain the high extent of oxidoreduction of deoxycholic acid, as discussed above.

12-ketolithocholic acid formed from deoxycholic acid by oxidation of the $12 \alpha$-hydroxyl group may be excreted as such in faeces where it constitutes one of the major bile acids. ${ }^{5-7}$ It may possibly also be reduced to a 3,12-dihydroxybile acid by the intestinal microflora. Absorption of 12-ketolithocholic acid from the intestine has been demonstrated indirectly by analysis of portal blood. ${ }^{2}$ Thus, monoketonic 3,12-oxygenated bile acids constitute about $10 \%$ of deoxycholic acid in portal venous blood. ${ }^{2}$ Most of these ketonic bile acids are probably efficiently reduced in the liver as bile normally contains only traces of ketonic bile acids. Increased amounts of monohydroxy-monoketonic bile acids in bile of cholecystectomised patients have, however, previously been obtained in some" ${ }^{\text {" }}$ but not in all investigations. ${ }^{15}$ Andersén et a $l^{17}$ recently reported an increased proportion of 12-ketolithocholic acid in bile of non-insulin-dependent diabetics and hypertriglyceridaemic patients. The results were interpreted to indicate that these patient groups may have an increased formation of secondary bile acids from cholic acid combined with a diminished capacity of the liver to reduce ketonic bile acids. None of our patients had diabetes or hypertriglyceridaemia.

The present study has shown that patients may have an abnormally high degree of oxidoreduction of a bile acid in the enterohepatic circulation in spite of a normal biliary bile acid composition. This, may have physiological implications as introduction of keto groups in a bile acid molecule may impair the degree of absorption from the intestine. An increased inflow of ketonic bile acids to the liver may possibly also influence the feed back regulation of bile acid formation and bile flow.

The technical assistance of Ms Gunvor Alvelius and Ms Ingela Svensson is gratefully acknowledged. This work was supported by grants from the Swedish Medical Research Council (03X-04793 and 03X3141) and Karolinska Institute.

\section{References}

1 Hylemon PB. Metabolism of bile acids in intestinal microflora. In: Danielsson H, Sjövall J, eds. Comprehensive biochemistry. Amsterdam: Elsevier, 1985; 12: $331-43$.

2 Björkhem I, Angelin B, Einarsson K, Ewerth S. Fasting levels of monoketonic bile acids in human peripheral and portal circulation. J Lipid Res 1982; 23: 1020-5.

3 Björkhem I, Daniclsson H. Biosynthesis and metabolism of bile acids in man. In: Popper H, Schaffner F, eds. Progress in liver diseases. New York: Grune \& Stratton, 1976: 5: 215-31.

4 Elliott WH. Metabolism of bile acids in liver and extrahepatic tissues. In: Daniclsson H, Sjövall J, eds. Comprehensive biochemistry. Amsterdam: Elscvicr. 1985; 12: 303-29.

5 Encroth P. Gordon B, Ryhage R, Sjövall J. Identification of mono- and dihydroxy bilc acids in human feces by gas-liquid chromatography and mass spectrometry. J Lipid Res 1966; 7: 511-23.

6 Encroth P. Hellström K, Sjövall J. A method for quantitative determination of bile acids in human feces. Acta Chem Scand 1968; 22: 1729-44.

7 Hill MJ, Aries VC. Faccal steroid composition and its relationship to cancer of the large bowel. J Pathol 1971; 104: 129-39.

8 Almond HR, Vlahcevic ZR, Bell CC Jr, Gregory DH, Swell L. Bile acid pools, kinetics and biliary lipid composition before and after cholecystectomy. N Engl J Med 1973; 289: 1213-6.

9 Malagelada JK, Go VLW, Sumerskill WHJ, Gamble WS. Bile acid secretion and biliary bile acid composition altered by cholecystectomy. Am J Dig Dis 1973; 18: 455-9.

10 Pomare EW, Heaton KW. The effect of cholecystectomy on bile salt metabolism. Gut 1973; 14: 753-62.

11 Hepner GW, Hofmann AF, Malagelada JR, Szczepanik PA, Klein PD. Increased bacterial degradation of bile acids in cholecystectomized patients. Gastroenterology 1974; 66: 556-64.

12 Roda E, Aldini R, Mazzella G, Roda A, Sama C, Festi D, Barbara L. Enterohepatic circulation of bile acids after cholecystectomy. Gut 1978; 19: 64()-9.

13 Björkhem I, Liljeqvist L, Nilsell K. Einarsson K. Oxidoreduction of different hydroxyl groups in bilc acids during their enterohepatic circulation in man. J Lipid Res 1986; 27: 177-82.

14 Encroth P. Thin-layer chromatography of bile acids. J Lipid Res 1963; 4: 11-4.

15 Adler RD, Metzger AL, Grundy SM. Biliary lipid secretion before and after cholecystectomy in American Indians with cholesterol gallstones. Gastroenterology 1976; 66: 1212-7.

16 van den Linden W, Katzenstein B, Nakayama F. The possible carcinogenic effect of cholecystectomy. No postoperative increase in the proportion of secondary bile acids. Cancer 1983; 52: 1265-8.

17 Andersén E, Karlaganis G, Sjövall J. Altered bile acid profiles in duodenal bile and urine in diabetic subjects. Eur J Clin Invest 1988; 18: 166-72. 